Acta Theriologica 41 (1): 73-82, 1996.

PL ISSN 0001-7051

\title{
Morphological investigations of the winter coat in white-tailed deer: Differences in skin, glands and hair structure of various body regions
}

\author{
George A. BUBENIK
}

\begin{abstract}
Bubenik G. A. 1996. Morphological investigations of the winter coat in white-tailed deer: Differences in skin, glands and hair structure of various body regions. Acta Theriologica 41: 73-82.

Skin and hair samples taken from seven body areas of a winter hair coat of a male and a female yearling white-tailed deer Odocoileus virginianus Zimmerman, 1780 were investigated morphologically. The color, length, diameter, density and relative proportion of guard and wooly hair was determined from the histological sections. In addition, the epidermal thickness, and the shape, density, location and structure of sebaceous and sudoriferous glands were also determined.A reciprocal relationship was found between the insulation values of the pelage, the epidermal thickness and the amount of either gland. The areas known to provide the best insulation (the tail and the belly) exhibited the thinnest epidermis, the highest density of hair and the highest concentration of sebaceous glands. In reverse, the region with the lowest insulation capacity (the leg) exhibits the thickest epidermis, the lowest hair density and the highest amount of sudoriferous glands.

Department of Zoology, University of Guelph, Guelph, Ontario, Canada N1G 2W1, Fax: (519) 7671656

Key words: Odocoilens virginianus, Cervidae, hair coat, morphology, histology, skin glands
\end{abstract}

\section{Introduction}

Morphological investigation of deer skin and pelage has been reported in several cervid species, such as the red deer Cervus elaphus (Schäffer 1940, Ryder and Kay 1973, Ryder 1977, Kay and Ryder 1978), roe deer Capreolus capreolus (Johnson and Leask 1977, Adams and Johnson 1980), pudu Pudu puda (Feder and Arias 1992), musk deer Moschus moschiferus (Frädrich 1966), white-tailed deer Odocoileus virginianus (Quay 1971), mule deer Odocoileus hemionus hemionus (Quay and Muller-Schwartze 1971), and reindeer and caribou Rangifer tarandus (Lewin and Stelfox 1967, Kallquist and Mossing 1978). Most of these studies were devoted either to the morphology of specialized skin glands (eg interdigital, tarsal, forehead, tail), as related to seasonal cycles or reported the histological picture of the seasonal coat change. Only rarely, were samples of skin taken from more than one specific area of the deer body (Kallquist and Mossing 1978). The present study 
attempts to fill the gap in our knowledge of the deer hair coat by comparing the variability in the structure of hair and upper integument of the various body regions of white-tailed deer Odocoileus virginianus Zimmerman, 1780. The characteristics of the pelage (guard hair and wooly hair) and the parameters of the integument (arrectores pili, sebaceous and suderiferous glands) were investigated in seven specific body areas of the winter coat of a white-tailed deer.

\section{Material and methods}

Small rectangles of skin (approx. $1 \times 3 \mathrm{~cm}$ ) were dissected from 7 body areas of healthy yearling white-tailed deer buck and doe, from roadkills found in December and February 1992/1993, respectively, around Guelph, southwest Ontario (latitude $42^{\circ} \mathrm{N}$ ). The following body regions were chosen for investigation: (1) midlateral neck area, (2) central interscapular area, (3) median lumbar area, (4) midlateral carpal region, (5) median abdominal area, (6) tail - mid superior section, (7) tail - mid inferior section (Fig. 1). The skin samples were first investigated macroscopically for the color and lengths of the guard and wooly hair and then microscopically for the hair diameter and shape. Fifty guard hair and fifty wooly hair chosen randomly from each region were measured and their average length was calculated. Small samples of the skin (approx. $1 \mathrm{~cm}^{2}$ ) were frozen to $-20^{\circ} \mathrm{C}$ and then cut longitudinally and transversally in a cryostat. The $20 \mu$ sections were first stained with Hematoxylin-Eosin and then representative sections were photographed. An average wooly and guard hair diameters and the guard hair density per $\mathrm{mm}^{2}$ were established from corresponding cross sections by measuring 50 hairs. In addition, the histological sections were investigated for the position and structure of the sudoriferous and sebaceous glands, the number and size of arrectores pili, the amount of collagen in each region, the shape of the surface epithelium and the ratio of wooly to guard hair.

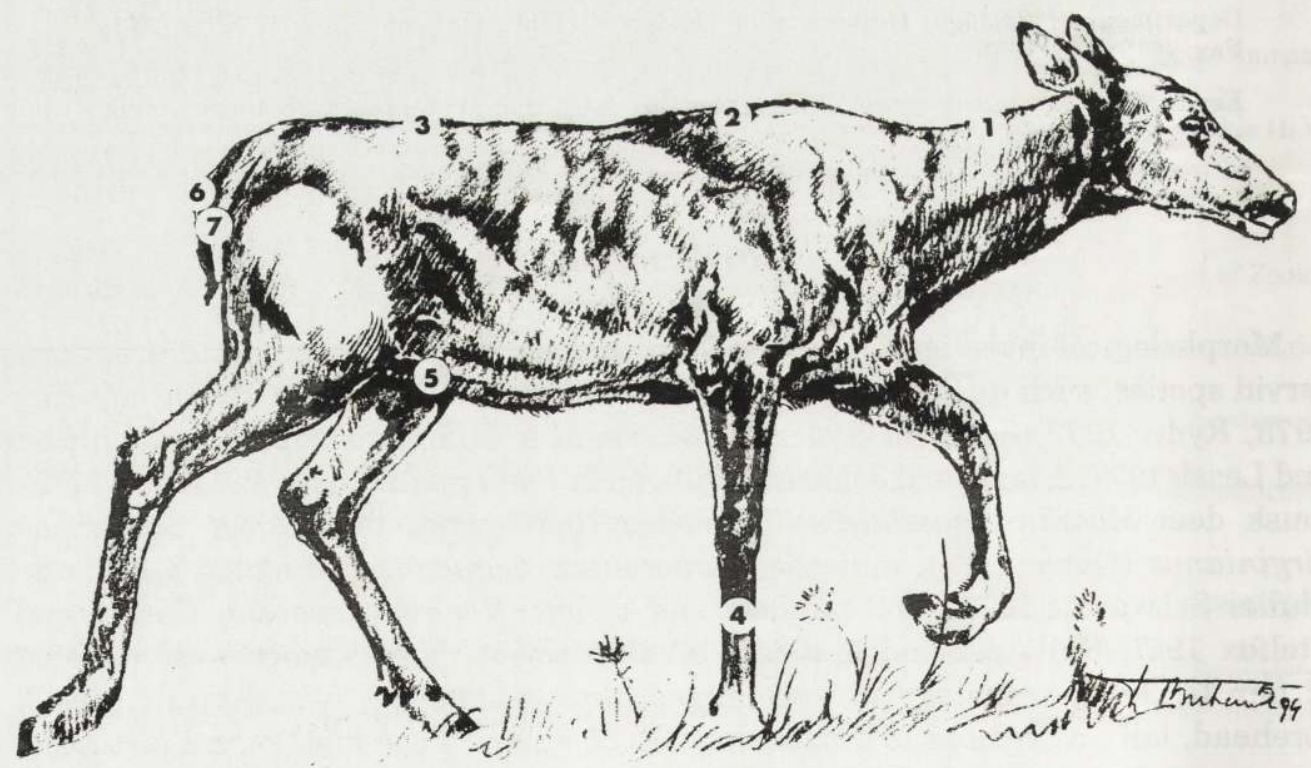

Fig. 1. Body regions investigated: (1) neck, (2) shoulder, (3) back, (4) leg, (5) belly, (6) upper tail, and (7) lower tail. 


\section{Results}

No substantial difference in coloration, diameter and density of hair was found between the sexes. However, the average length of the guard hair from various body areas was on average about $30 \%$ shorter in the buck than in the doe. As this was most probably due to the difference in the time of death (December versus February), it was decided to present tabulated data only in the female in which the coat was most fully developed.

\section{Hair}

Color and structure: The guard hair are mostly grey to brown with reddish or beige tips. Black tipped hair is found in the face area; the hair on the belly and the inferior part of the tail are purely white. Detail description of the color in various body regions is presented in Table 1 . The guard hair are mostly straight with the largest amount of pigment located in the medulla, except on the underside of the tail and the belly areas, where the guard hair are curly and white. The wooly hair is thin, distinctly curly and are almost colorless, mostly appearing opaque white. The general ratio of guard hair to wooly hair in most body areas was approximately $1: 2$ except for the tail regions where fewer wooly hair were

Table 1. Morphological parameters of hair and skin in the winter coat of white-tailed deer.

\begin{tabular}{|c|c|c|c|c|c|c|c|}
\hline \multirow[b]{2}{*}{ Area } & \multirow[b]{2}{*}{$\begin{array}{l}\text { Hair color } \\
\text { of gard hair }\end{array}$} & \multicolumn{3}{|c|}{ Guard hair } & \multicolumn{2}{|c|}{ Wooly hair } & \multirow{2}{*}{$\begin{array}{l}\text { Epidermis } \\
\text { thickness } \\
\quad(\mathrm{mm}) \\
( \pm \mathrm{SE})\end{array}$} \\
\hline & & $\begin{array}{l}\text { length } \\
(\mathrm{mm}) \\
( \pm \mathrm{SE})\end{array}$ & $\begin{array}{l}\text { diameter } \\
\qquad(\mathrm{mm}) \\
( \pm \mathrm{SE})\end{array}$ & $\begin{array}{l}\text { density } \\
\left(\mathrm{mm}^{2}\right) \\
( \pm \mathrm{SE})\end{array}$ & $\begin{array}{l}\text { length } \\
(\mathrm{mm}) \\
( \pm \mathrm{SE})\end{array}$ & $\begin{array}{l}\text { diameter } \\
\text { (mm) } \\
( \pm \mathrm{SE})\end{array}$ & \\
\hline $1 \mathrm{Neck}$ & $\begin{array}{l}\text { Mostly gray with } \\
\text { light beige tips }\end{array}$ & $\begin{array}{c}63 \\
(3.17)\end{array}$ & $\begin{array}{c}0.20 \\
(0.03)\end{array}$ & $\begin{array}{c}4.30 \\
(0.98)\end{array}$ & $\begin{array}{c}31 \\
(1.21)\end{array}$ & $\begin{array}{c}0.020 \\
(0.002)\end{array}$ & $\begin{array}{c}0.02 \\
(0.002)\end{array}$ \\
\hline 2 Shoulder & $\begin{array}{l}\text { Proximal half is mostly } \\
\text { gray, the distal half is most- } \\
\text { ly brown with beige tips }\end{array}$ & $\begin{array}{c}51 \\
(2.46)\end{array}$ & $\begin{array}{c}0.26 \\
(0.03)\end{array}$ & $\begin{array}{c}3.25 \\
(0.76)\end{array}$ & $\begin{array}{c}23 \\
(1.15)\end{array}$ & $\begin{array}{c}0.025 \\
(0.003)\end{array}$ & $\begin{array}{c}0.02 \\
(0.003)\end{array}$ \\
\hline 3 Back & Same as in the region 2 & $\begin{array}{c}66 \\
(3.22)\end{array}$ & $\begin{array}{c}0.31 \\
(0.03)\end{array}$ & $\begin{array}{c}1.97 \\
(0.46)\end{array}$ & $\begin{array}{c}39 \\
(1.26)\end{array}$ & $\begin{array}{c}0.020 \\
(0.002)\end{array}$ & $\begin{array}{c}0.02 \\
(0.003)\end{array}$ \\
\hline $4 \mathrm{Leg}$ & $\begin{array}{l}\text { Proximal half is gray, } \\
\text { the distal is brown with } \\
\text { reddish-beige tips }\end{array}$ & $\begin{array}{c}17 \\
(1.61)\end{array}$ & $\begin{array}{c}0.13 \\
(0.02)\end{array}$ & $\begin{array}{l}2.30 \\
(0.53)\end{array}$ & $\begin{array}{c}8 \\
(0.17)\end{array}$ & $\begin{array}{l}0.015 \\
(0.001)\end{array}$ & $\begin{array}{c}0.03 \\
(0.004)\end{array}$ \\
\hline 5 Belly & Pure white & $\begin{array}{c}82 \\
(4.03)\end{array}$ & $\begin{array}{c}0.19 \\
(0.09)\end{array}$ & $\begin{array}{c}2.55 \\
(0.51)\end{array}$ & $\begin{array}{c}61 \\
(2.34)\end{array}$ & $\begin{array}{c}0.020 \\
(0.002)\end{array}$ & $\begin{array}{c}0.01 \\
(0.001)\end{array}$ \\
\hline 6 Tail up & $\begin{array}{l}\text { Proximal part brown, } \\
\text { distal reddish-beige }\end{array}$ & $\begin{array}{c}135 \\
(5.32)\end{array}$ & $\begin{array}{c}0.12 \\
(0.06)\end{array}$ & $\begin{array}{c}4.46 \\
(1.03)\end{array}$ & $\begin{array}{c}94 \\
(2.76)\end{array}$ & $\begin{array}{l}0.020 \\
(0.002)\end{array}$ & $\begin{array}{c}0.01 \\
(0.001)\end{array}$ \\
\hline 7 Tail down & $\begin{array}{l}\text { Pure white, curly, } \\
\text { like wooly hair }\end{array}$ & $\begin{array}{c}142 \\
(6.65)\end{array}$ & $\begin{array}{c}0.18 \\
(0.05)\end{array}$ & $\begin{array}{c}3.64 \\
(0.72)\end{array}$ & $\begin{array}{c}70 \\
(2.14)\end{array}$ & $\begin{array}{c}0.020 \\
(0.002)\end{array}$ & $\begin{array}{c}0.01 \\
(0.001)\end{array}$ \\
\hline
\end{tabular}




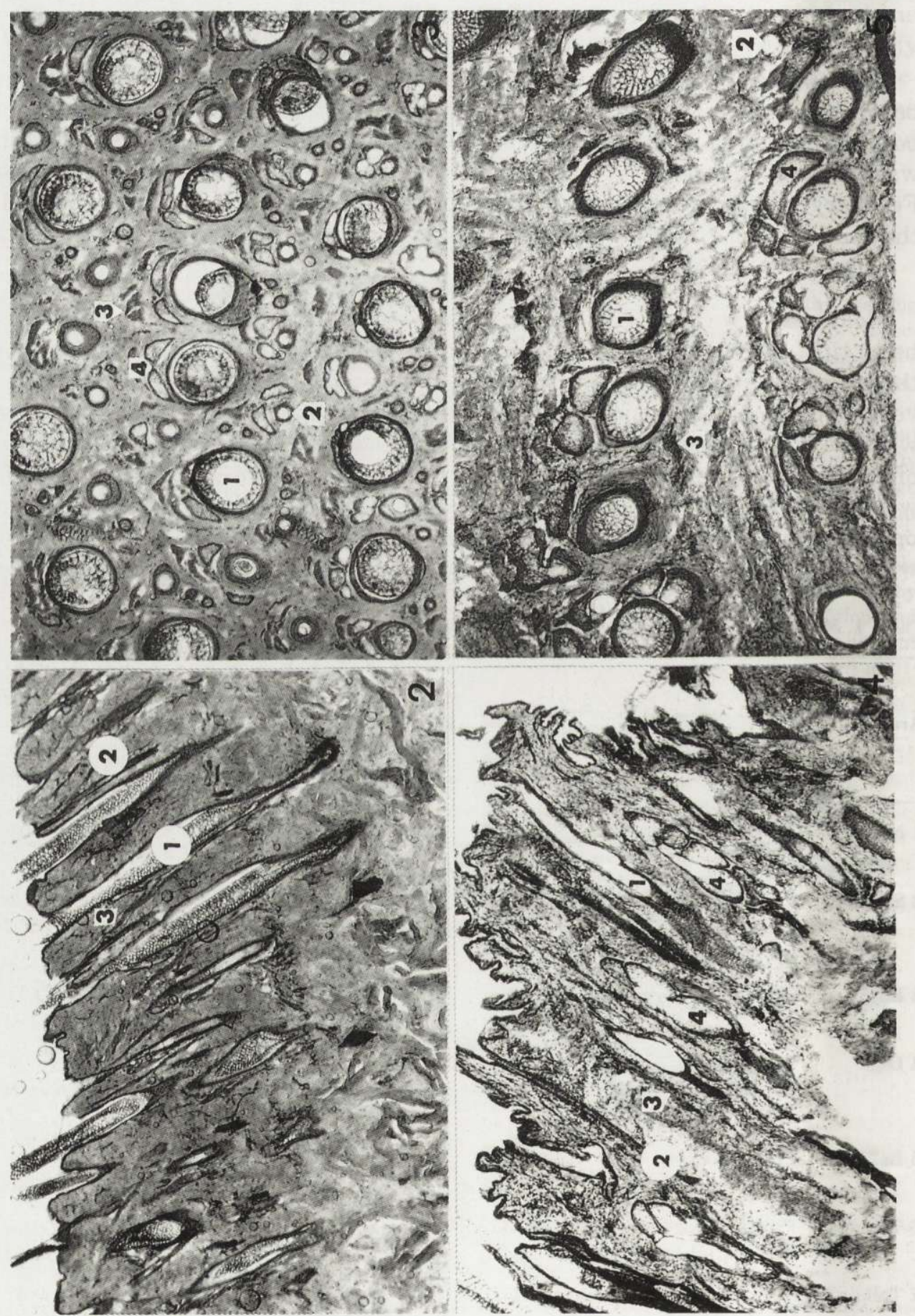




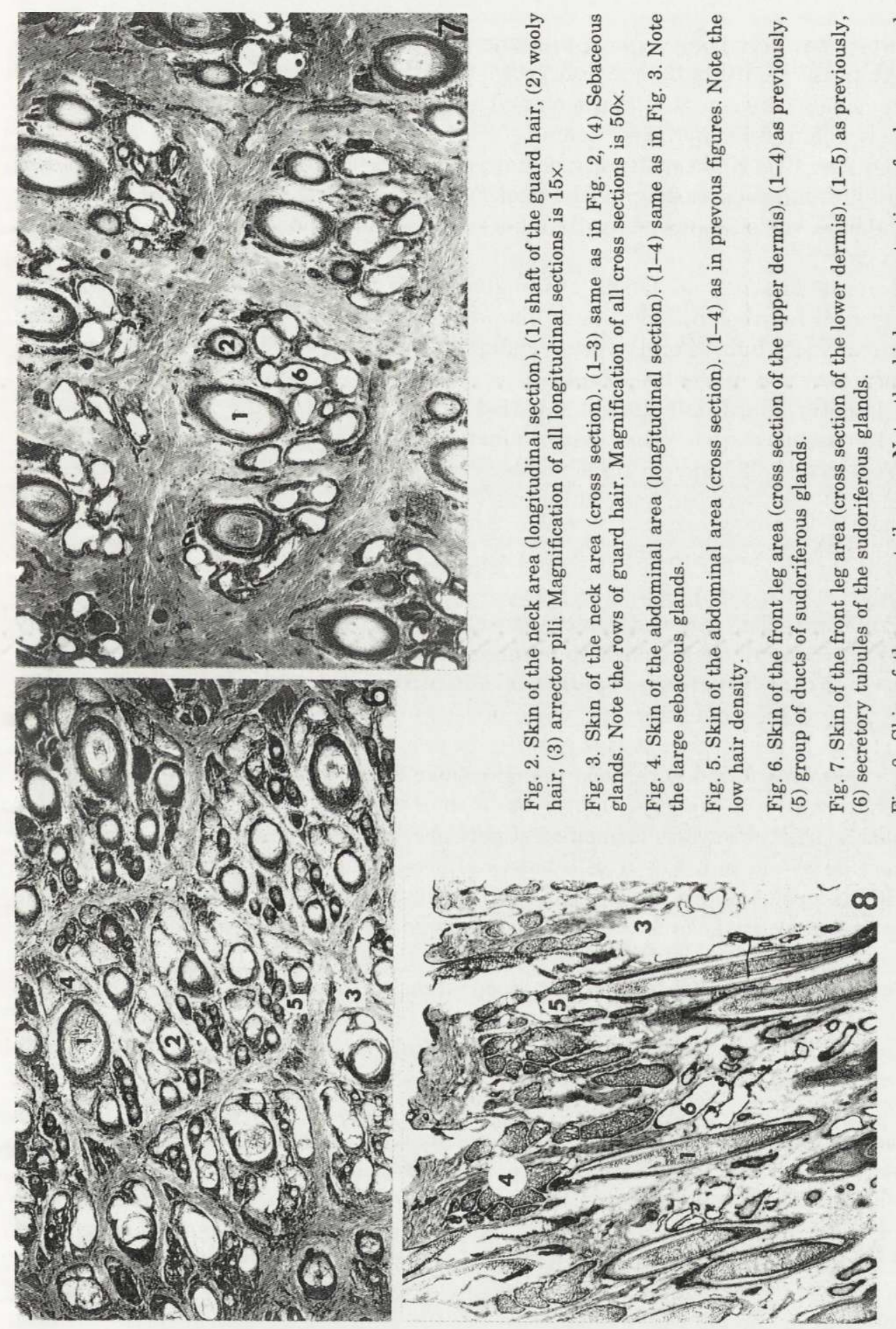


detected. In most body regions the length of the wooly hair is about $50 \%$ of the length of the guard hair. The hair grows in distincts rows (Fig. 3) with wooly hair sandwiched between the guard hair. The most distinct arrangement of hair in rows was found in the belly region.

Density: The highest density of hair per $\mathrm{mm}^{2}$ was detected in the upper tail area (4.5), followed closely by the neck (4.3). The lowest density (2.0) was found in the back region followed by the leg area (2.3). Additional data are presented in the Table 1.

Length: The average length of the guard hair ranges from $17 \mathrm{~mm}$, detected in the frontal leg region, to $142 \mathrm{~mm}$, found on the superior section of the tail. The shortest wooly hair $(8 \mathrm{~mm})$ were registered on the leg, the longest $(94 \mathrm{~mm})$ in the superior section of the tail (Table 1).

Diameter: Gard hair diameter varied from $0.13 \mathrm{~mm}$ in the leg region to 0.31 $\mathrm{mm}$ in the back area. Wooly hair diameter varied from $0.015 \mathrm{~mm}$ in the frontal leg region to $0.025 \mathrm{~mm}$ in the shoulder area. The greatest variability in the hair diameters was found in both tail areas (Table 1).

Skin

Epidermis: The thinnest epidermis was detected in both tail areas and the belly region $(0.01 \mathrm{~mm})$, the thickest epidermis was found in the leg skin $(0.03 \mathrm{~mm})$. The rest of the body exhibits epidermis of aproximately $0.02 \mathrm{~mm}$. Whereas the thickness of the epidermis was more or less uniform in all regions investigated, the shape of the surface varies greatly. In the belly region (Fig. 4) the surface is extremely convoluted with deep invaginations into the dermis. Similar structure was also found in the superior region of the tail. However in the neck, shoulder or back areas the surface formed relatively low, regularly spaced undulations. The underside of the tail (Fig. 8) is almost uniformly flat.

Sudoriferous glands (SUG): The bulk of these glands is located almost tvice as deep (as measured from the epidermis) as most sebaceous glands (SBG). The highest concentration of SUG was detected in the skin of the front leg (Figs 6 and 7), where they are located in the deep areas of the dermis (Fig. 7) which is infiltrated with a massive amount of collagen fibers. The neck, shoulder and back areas exhibit approximately the same moderate amount of SUG. These glands usually have a wider lumen, especially in the shoulder area and are embedded in a small amount of collagen fibers. In the tail regions (Figs 7 and 8), the SUG are more common then in the neck, shoulder or back areas. Here they are bcated closer to the surface, right under the SBG, especially in upper tail region. Only few collagen fibers were found in the dermis of the tail skin but unlike in the other body areas, small islets of fat cells were found interspersed between and just below the hair follicles. The lowest number of SUG was observed in the belly area (Fig. 4) which exhibits a heavy lymphatic infiltration and a moderate anount of collagen in the dermis. 
Sebaceous glands: The highest amount of SBG was located in the inferior and superior parts of the tail (Figs 7 and 8), where the glands are large, multilobulated and located very close to the surface. In the tail regions the SBG form almost an uninterrupted layer of glandular tissue. The second highest concentration was found in the belly area (Figs 4 and 5) where SBG are also large, multilobulated but located slightly deeper than in the tail section. The SBG of all other areas are mostly simpler structures of highly tubular form (Fig. 3). Very few SBG were detected in the skin of the front leg where they are located in the most superficial areas of the dermis (Fig. 6).

Arrectores pili: Only rudimentary arrectores pili (AP) were located in the belly region (Figs 4 and 5). A moderate to more substantial amount was found in the leg, neck, shoulder and back regions (Figs 2 and 3). The highest amount of smooth muscles was found in both areas of the tail where thick strands surrounded the SBG and filled almost half of the spaces between hair shafts (Fig. 8). These smooth muscles were much thicker than the regular AP found in other skin regions.

\section{Discussion}

Pelage is a unique product of the mammalian skin which is best suited to protect each individual species. The main functions of the pelage is to maintain an integrity of an internal environment, provide camouflage, help in thermoregulation and foster intraspecific communication. Besides hair, the other skin derivatives such as the skin glands and skin muscles help deer to survive the impact of climatic changes. In all cervids, the pelage characteristics vary considerably between individual body areas. Because of its protective function, and its role in intersexual communication, the differences are more pronounced in the winter coat than in the summer coat. The generally darker color (grey, brown or black) found on the external surface of white-tailed deer serve as camouflage. The pure white color of the abdominal hair may counteract the shadow cast by the body and thus help the deer to blend with their environment (Dobie 1990).

The primary (guard) hair are generally coarse and long, and their medulla contain melanin. The secondary (wooly) hair (or underfur) are thinner, highly convoluted, generally $50 \%$ shorter than the guard hair, contain no medulla and reach high density (Ryder 1977, Kay and Ryder 1978). The length of the hair in deer not only correlates with the requirement to insulate and protect the skin but also with other factors, such as the capacity to hold on snow and ice in the exposed areas. Therefore, the shortest guard and wooly hair are found on extremities and the longest hair on the underside of the tail. The long, pure white, curly filaments of the tail hair can significantly protect the relatively exposed circumanal area. However, its main function is probably in communication; like a white flag, an elevated tail signals danger to conspecifics. The diameter of guard hair and wooly hair filaments is fairly uniform across the main body cover. That the thinnest hair 
(guard as well as wooly) are located in the leg area indicates that this region either does not require any special thermal protection or that the need to prevent accumulation of frozen snow on leg hair supersedes the need for insulation. The longest hair, providing the best thermal protection was detected in the belly area; However, unlike in the other regions, the wooly hair there reached around $75 \%$ of the length of the guard hair.

The sudoriferous glands (sweat glands) in cervids were earlier called apocrine glands. Although the larger diameter and the deeper location in some skin regions may resemble the apocrine glands, they nevertheless open to the skin surface instead of to the hair shaft as true apocrine glands do. Furthermore, there is no clear scientific evidence, that most of these glands produce any pheromones (Quay and Muller-Schwartze 1971). Finally, the physiological function of the SUG is to produce sweat. However, to my knowledge no study has attempted to investigate the role of sweat production in cervid thermoregulation. However, the large number of SUG in the leg area would support some role in evaporative cooling suggested by Kallquist and Mossing (1978), as this region is the most exposed to the effect of convection.

The sebaceous glands are most prominent in the underside of the tail area where they might be involved in the impregnation of the long white hair covering the exposed circumanal region. However, as a large concentration of SBG was also found in the upper tail areas it may be speculated that perhaps these glands are producing signal pheromones. These would be released during the period of alarm when the deer's tail is moving up. The thick bundles of smooth muscles which surround the SBG, might be able to squeeze the pheromones out of the superficially located glands. The thick strands of muscles enveloping SBG resemble the smooth muscles surrounding the secretory glands of the prostate which cause the release of the prostatic secretion during ejaculation. The thin, but relatively dense hair in the tail areas (especially in the white underside) would serve as an ideal dispenser of pheromones released from SBG. Generally distributed SG are probably not significant in olfactory communication, however, some specialized SG are important source of pheromones (Quay 1977). The possibility of pheromones-secreting caudal glands was already discussed by Quay and Muller-Schwarze (1971) who also speculated that arrectores pili muscles may be used for ejection of sebum in response to emotion. Similarly to white-tailed deer, enlarged caudal glands were also reported in red deer (Schäffer 1940), mule deer (Quay and Muller-Schwartze 1971), woodland caribou (Lewin and Stelfox 1967), and musk deer (Frädrich 1966).

The second highest density of SBG was found in the belly area, which is another location associated with the long, white guard hair. The massive production of water-repellent sebum in the abdominal area may prevent moisture from reaching the skin in the laying deer. Surprisingly low density of SBG was detected in the main areas of the body covering and the region of the leg. This may indicate that 
the thick undercoat (wooly hair) combined with the tough guard hair does not require any great amount of repellent to insulate the skin from the effect of water.

The epidermis of the body skin is approximately $5-15 \times$ thinner than the epidermis of the antler velvet skin (Bubenik 1993). That indicates that the body skin but not the velvet skin is involved in thermoregulation by thermal convection. Therefore, the areas with the longest hair (tail and belly) exhibited the thinnest epidermis. On the other hand, in the leg region the priority is the protection from abrasion and thermoregulation by evaporative cooling. Therefore, this area has the thickest epithelium, the greatest amount of sudoriferous glands and the lowest hair density.

It can be concluded, that a reciprocal relationship exists between the insulation values of the pelage, the epidermal thickness and the amount of either glands. The areas providing the best insulation (tail and belly) have the thinnest epidermis, the highest density of hair and the highest concentration of sebaceous glands. In reverse, the region with the lowest insulation values (the leg) exhibits the thickest epidermis, the lowest hair density and the highest amount of the sudoriferous glands.

Acknowledgments: This paper is dedicated to the memory of my father, a retired deer biologist, A. B. Bubenik, who died suddenly in February of 1995 . He provided valuable comments on the text of this manuscript and made the drawing of the Fig. 1.

\section{References}

Adams M. G. and Johnson E. 1980. Seasonal changes in the skin glands of Roe deer (Capreolus capreolus). Journal of Zoology 191: 509-520.

Bubenik G. A. 1993. Morphological differences in the velvet of Cervidae. [In: Deer of China. N. Ohtaishi and H. I. Sheng, eds]. Elsevier, Amsterdam: 156-164.

Dobie D. 1990. Bucks of many colors. North American White-tail 9: 53, 54, 56-59.

Feder F-H. and Arias P. 1992. Vergleichende Untersuchungen an Haaren von Pudu pudu und europaischen Cerviden. Anatomie, Histologie und Embryologie 21: 76-81.

Frädrich H. 1966. Einige Verhaltungsbeobachtungen am Moschustier (Moschus moschiferus L.). Der Zoologische Garten 33: 65-78.

Johnson E. and Leask J. T. S. 1977. Metabolism of testosterone by forehead skin of the roebuck (Capreolus capreolus). Journal of Endocrinology 75: 363-372.

Kallquist L. and Mossing T. 1978. The distribution of sudoriferous glands in the hairy skin of reindeer (Rangifer tarandus L.). Acta Zoologica 58: 65-68.

Kay R. N. B. and Ryder M. L. 1978. Coat growth in Red deer (Cervus elaphus) exposed to a day-length cycle of six month duration. Journal of Zoology 185: 505-510.

Lewin V. and Stelfox J. G. 1967. Functional anatomy of the tail and associated glands in woodland caribou. Canadian Field Naturalist 81: 63-66.

Quay W. B. 1971. Geographic variation in the metatarsal "gland" of the white-tailed deer (Odocoileus virginianus). Journal of Mammalogy 52: 1-11.

Quay W. B. 1977. Structure and function of skin glands. [In: Chemical signals in vertebrates. D. Muller-Schwartze and M. M. Mozell, eds]. Plenum Publishing Corp., New York: 1-16.

Quay W. B. and Muller-Schwartze D. 1971. Relations of age and sex to integumentary glandular regions in rocky mountain mule deer (Odocoileus hemionus hemionus). Journal of Mammalogy 52: $670-685$. 
Ryder M. L. 1977. Seasonal coat changes in grazing Red deer (Cervus elaphus). Journal of Zoology 181: 137-143.

Ryder M. L. and Kay R. N. B. 1973. Structure and seasonal change in the coat of Red deer (Cervus elaphus). Journal of Zoology 170: 69-77.

Schäffer J. 1940. Die Hautdrüsenorgane der Säugetiere mit besonderer Berücksichtigung ihres histologischen Aufbaues und Bemerkung über Proktodaaldrüsen. Urban und Schwarzenberg, Berlin and Wien: 1-464.

Received 6 May 1995, accepted 23 September 1995. 